\title{
Treatment for primary hypothyroidism: current approaches and future possibilities
}

This article was published in the following Dove Press journal:

Drug Design, Development and Therapy

2I December 20II

Number of times this article has been viewed

\author{
Ali J Chakera' \\ Simon HS Pearce ${ }^{2}$ \\ Bijay Vaidya' \\ 'Department of Endocrinology, Royal \\ Devon and Exeter Hospital and \\ Peninsula Medical School, Exeter, \\ ${ }^{2}$ Endocrine Unit, Royal Victoria \\ Infirmary and Newcastle University, \\ Newcastle upon Tyne, UK
}

\begin{abstract}
Primary hypothyroidism is the most common endocrine disease. Although the diagnosis and treatment of hypothyroidism is often considered simple, there are large numbers of people with this condition who are suboptimally treated. Even in those people with hypothyroidism who are biochemically euthyroid on levothyroxine replacement there is a significant proportion who report poorer quality of life. This review explores the historical and current treatment options for hypothyroidism, reasons for and potential solutions to suboptimal treatment, and future possibilities in the treatment of hypothyroidism.
\end{abstract}

Keywords: primary hypothyroidism, levothyroxine, triiodothyronine, thyroid-stimulating hormone, thyroid

\section{Introduction}

Primary hypothyroidism or thyroid hormone deficiency due to abnormality in the thyroid gland is the most common endocrine disease. The prevalence of hypothyroidism in the general population ranges from 3.8\%-4.6\%. ${ }^{1-4}$ The Whickham survey showed an annual incidence of hypothyroidism of 4.1 per 1000 in women and 0.6 per 1000 in men. ${ }^{2}$ Furthermore, a more recent study from the UK suggests that the incidence of hypothyroidism is rising, ${ }^{3}$ although there appears to be geographical variation. For example, epidemiological studies suggest Denmark has nine times fewer new cases of hypothyroidism than the UK. ${ }^{5}$ In the UK, over 23 million prescriptions for levothyroxine were written in 2010, making it the third most prescribed medication after simvastatin and aspirin. ${ }^{6}$

Diagnosis and treatment of hypothyroidism is often considered simple and is mostly carried out in a primary care setting. However, studies continue to show problems in the management of this condition. Many patients on thyroid hormone replacement are either under-replaced or over-replaced ${ }^{7-10}$ and a significant number of patients on thyroid hormone replacement report not feeling well despite having thyroid function tests within the healthy reference range. ${ }^{11}$ In this review, we discuss current approaches to the management of primary hypothyroidism and explore potential future developments.

\section{Causes of primary hypothyroidism}

In Western countries, the most common cause of primary hypothyroidism is autoimmune thyroiditis. However, in many parts of the world, iodine deficiency remains an important cause. Other common causes of hypothyroidism include thyroidectomy, radioiodine therapy, and drugs such as amiodarone, lithium, thionamide, iodine, interferon, sunitinib, rifampicin, and thalidomide. Transient hypothyroidism may occur in 
subacute (de Quervain's) thyroiditis and also in postpartum thyroiditis. In both of these conditions $75 \%-85 \%$ of patients regain normal thyroid function. ${ }^{12}$ Congenital hypothyroidism, due to thyroid gland agenesis or dyshormonogenesis, affects about one in 4000 newborns and is the commonest congenital endocrinopathy. ${ }^{13}$

\section{Diagnosis of primary hypothyroidism}

The common clinical features associated with hypothyroidism are tiredness, weight gain, dry skin, cold intolerance, constipation, muscle weakness, puffiness around the eyes, hoarse voice, and poor memory. However, a study surveying thyroid disease in Colorado has shown that the sensitivity of individual symptoms ranges from $2.9 \%$ to $24.5 \%$. ${ }^{7}$ Although the likelihood of hypothyroidism increases with increasing numbers of symptoms, ${ }^{7,14}$ absence of symptoms does not exclude the diagnosis. Furthermore, these symptoms are nonspecific and common in the euthyroid population with around $20 \%$ of euthyroid subjects having four or more hypothyroid symptoms. $^{7}$ Therefore, the diagnosis of hypothyroidism must be made biochemically.

Overt primary hypothyroidism is diagnosed biochemically with a serum thyroid stimulating hormone (TSH) concentration above the reference range and low free T4. If the TSH is raised but free T4 is in the normal range then this is referred to as subclinical hypothyroidism. The population reference range of TSH is around $0.4-4.5 \mathrm{mIU} / \mathrm{L}$ and most patients with overt hypothyroidism have TSH above $10 \mathrm{mIU} / \mathrm{L}$. However, several controversies surrounding the TSH reference range have surfaced in recent years. Firstly, because the TSH in the general population is not normally distributed, and more than $95 \%$ of healthy individuals have TSH less than $2.5 \mathrm{mIU} / \mathrm{L}$, it has been suggested that the upper limit of the TSH reference range may be skewed by occult thyroid dysfunction, ${ }^{15}$ leading to a debate whether the upper limit of the TSH reference range should be lowered from 4.5 to $2.5 \mathrm{mIU} / \mathrm{L} .{ }^{16-18}$ Secondly, in pregnancy, it is now recognized that trimesterspecific reference ranges for TSH should be used to assess thyroid function; when trimester-specific reference ranges are not available, TSH of $2.5 \mathrm{mIU} / \mathrm{L}$ in the first trimester and $3 \mathrm{mIU} / \mathrm{L}$ in the later trimesters are considered as the upper limits of the reference range. ${ }^{19,20}$ Thirdly, because the TSH distribution and reference limits are influenced by age and ethnicity, the use of age and race-standardized TSH reference ranges has also been suggested. ${ }^{21}$ Finally, it has been shown that variation of TSH within an individual is narrower than the variation in the general population, supporting the concept of an individual reference range, such that a TSH level within the population reference range may still be abnormal for the individual. ${ }^{22}$ It is thought that genetic factors play a part in influencing the thyroid set-point in the individual. This is supported by studies showing associations between TSH and common variations in different genes, including $P D E 8 B$ and $T S H R,{ }^{23-26}$ and a study showing that a common variation in the $P D E 8 B$ gene influences TSH reference ranges in pregnant women. ${ }^{27}$

\section{Treatment of primary hypothyroidism Historical perspective}

By the end of the 19th century, myxedema had been attributed to diminished thyroid function and a cretinism-like condition (also described as cachexia strumipriva) had been observed following thyroidectomy in animals and humans. ${ }^{28}$ Moreover, xenotransplantation of animal thyroid gland had been shown to improve symptoms in women suffering from myxedema temporarily. In 1891, Murray described the first regime of thyroid hormone replacement, subcutaneously injecting extract of sheep thyroid into a patient with hypothyroidism. ${ }^{29}$ It was soon shown that oral administration of thyroid extract was as effective. ${ }^{30}$ In 1914, Kendall purified thyroxine crystals, which became commercially available. Harrington identified the structure of thyroxine in 1926 and synthetic thyroxine was available for clinical use by the 1930s. However, it took many more years before thyroxine became preferable to desiccated thyroid extract as the treatment of choice for hypothyroidism. ${ }^{28}$ In 1952, Gross and Pitts-River identified the more potent liothyronine. ${ }^{31}$

\section{Dosage of levothyroxine}

Levothyroxine is the treatment of choice for hypothyroidism. It has a 7 day half-life, allowing daily dosing. ${ }^{12}$ A randomized controlled trial has shown that, in patients with no significant comorbidities, initiation of levothyroxine at a full dose based on body weight $(1.6 \mu \mathrm{g} / \mathrm{kg} /$ day $)$ is safe, effective, and requires fewer resources than using a more traditional approach of starting with a small dose and gradually titrating upward. ${ }^{32}$ The exceptions to this are the elderly and patients with known ischemic heart disease (see the "Levothyroxine replacement in special circumstances" section of this review).

\section{Timing of levothyroxine}

Conventionally, hypothyroid patients are advised to take levothyroxine on an empty stomach half an hour before breakfast to prevent impairment of absorption by food. Several recent studies have looked at whether a bedtime dosage of levothyroxine is preferable. A small nonrandomized study 
involving eleven hypothyroid patients on a stable dose of morning levothyroxine found a decrease in mean TSH and an increase in free thyroid hormone levels when the timing of levothyroxine dosage was changed to bedtime. ${ }^{33}$ The same investigators, in a subsequent randomized double-blind crossover trial of 105 consecutive patients, have reaffirmed that biochemical control was best achieved by night-time dosing. Taking levothyroxine at bedtime resulted in a decrease in mean TSH of $1.25 \mathrm{mIU} / \mathrm{L}$ (95\% confidence interval [CI] 0.60-1.89), and an increase in free T4 of $0.07 \mathrm{ng} / \mathrm{dL}$ (95\% CI 0.02-0.13) and total T3 of $6.5 \mathrm{ng} / \mathrm{dL}$ (95\% CI 0.9-12.1). ${ }^{34}$ However, there were no improvements in quality of life scores, blood pressure, or lipid profile. A retrospective study of 15 elderly patients in a nursing home showed a nonsignificant decrease in mean TSH of $0.29 \mathrm{mIU} / \mathrm{L}$ when the time of administration of levothyroxine was changed from early morning to midnight. ${ }^{35}$ In contrast, a randomized crossover trial in the US compared taking levothyroxine in the fasting state, with breakfast, or at bedtime in 65 patients with primary hypothyroidism and thyroid cancer, and found that TSH levels were significantly lower and less variable when levothyroxine was taken in the fasting state than at other times. ${ }^{36}$ Furthermore, Rajput et al randomized 77 patients with newly diagnosed autoimmune hypothyroidism to taking their levothyroxine half an hour before breakfast or two hours after their evening meal, and found no difference in TSH, lipid profile, clinical symptoms, quality of life scores, or the dose required to achieve euthyroidism between the two groups. ${ }^{37}$ The conflicting findings of different studies may reflect heterogeneity in the conditions of patients studied (for example, newly diagnosed patients versus patients on a stable dose of levothyroxine, and patients with thyroid cancer versus patients with autoimmune hypothyroidism) as well as in eating habits in relation to bedtime in the different study populations. Nevertheless, these studies suggest that bedtime dosing of levothyroxine could be tried as an alternative strategy in those patients who have problems in taking morning levothyroxine on an empty stomach.

\section{Monitoring thyroid function during levothyroxine replacement}

When initiating levothyroxine therapy, serum TSH should be measured to monitor for adequate replacement. TSH can take up to 4 months to normalize, even when starting on a full dose replacement regimen, due to thyrotroph hyperplasia. It is recommended that the TSH is measured 6-8 weeks after initiation of, or a change in levothyroxine dose. Once the patient is on a stable dose of levothyroxine, annual monitoring of TSH is recommended, although a retrospective study suggests that the monitoring interval could be safely increased to 18 months. ${ }^{38}$ Common causes of persistently elevated TSH in patients on levothyroxine replacement are shown in Table 1.

It is generally recommended to aim for a TSH in the lower half of the normal range, ie, typically $<2.5 \mathrm{mIU} / \mathrm{L}$ in patients with primary hypothyroidism on levothyroxine replacement. ${ }^{12,39}$ In a small study of 21 patients with primary hypothyroidism, titrating the dose of levothyroxine until the TSH was at the lower end of reference range or suppressed below the reference range was found to be associated with improved wellbeing in some patients. ${ }^{40}$ However, this observation was not confirmed by a double-blind randomized crossover trial, which has shown that small changes in levothyroxine dose to achieve a lower TSH do not result in an improved quality of life score. ${ }^{41}$ Furthermore, in a recent prospective study of 42 patients initiating levothyroxine treatment for newly diagnosed primary hypothyroidism, there was no difference in lipid profile, body composition, or bone mineral density in patients maintained on low TSH (0.4-2.0 $\mathrm{mIU} / \mathrm{L})$ as compared with those maintained on higher TSH (2-4 mIU/L) for 12 months, although resting energy expenditure was higher in patients maintained on the lower TSH target. ${ }^{42}$ Finally, overtreatment with levothyroxine leading to a suppressed TSH of below $0.1 \mathrm{mIU} / \mathrm{L}$ has been shown to be associated with adverse skeletal health, particularly in the elderly (see below). Taken together, these observations suggest that the target TSH level for most nonpregnant patients with primary hypothyroidism on levothyroxine replacement should be the population reference range and one should not necessarily increase the dose of levothyroxine in asymptomatic people with a TSH in the upper half of the normal range.

\section{Drug interactions with levothyroxine}

Several medications, supplements, and food can interfere with the absorption and action of levothyroxine (Table 2). Common drugs that can affect levothyroxine absorption

Table I Causes of persistently elevated thyroid-stimulating hormone in a patient on levothyroxine replacement

- Inadequate levothyroxine dose

- Poor compliance with medication (biochemistry usually showing high thyroid-stimulating hormone with normal free T4)

- Interaction with concomitant drugs (see Table 2)

- Taking levothyroxine with food

- Malabsorption

- Coexisting celiac disease or autoimmune gastritis

- Interference with the laboratory assay due to heterophil antibodies

- Coexisting thyroid hormone resistance (rare)

Abbreviation: T4, thyroxine 
Table 2 Substances that interact with levothyroxine

\begin{tabular}{l} 
Drugs and supplements that decrease the effect \\
of levothyroxine \\
Reduced levothyroxine absorption \\
Iron \\
Calcium carbonate \\
Cholestyramine \\
Aluminum \\
Cimetidine \\
Sucralfate \\
lodine (includes kelp tablets) \\
Selenium \\
Magnesium \\
Zinc \\
Soya \\
Fiber \\
Caffeine \\
Antacids \\
Increased levothyroxine clearance \\
Phenytoin \\
Carbamazepine \\
Phenobarbital \\
Rifampicin \\
Increased levothyroxine binding \\
Estrogen hormone replacement therapy \\
Drugs affected by levothyroxine \\
Drug effect enhanced by levothyroxine \\
Warfarin \\
Amitriptyline \\
Drug effect decreased by levothyroxine \\
Propranolol \\
\hline
\end{tabular}

include iron, calcium, cholestyramine, and aluminum and levothyroxine must be taken at least 4 hours apart from these drugs. Enzyme inducers, such as phenytoin, carbamazepine, phenobarbital, and rifampicin can increase the clearance of levothyroxine, necessitating an increased dose. Of women starting estrogen hormone replacement treatment, $35 \%$ were shown to need an increase in levothyroxine dose, thought to be due to increased thyroxine-binding globulin. ${ }^{43}$ It is noteworthy that hypothyroidism itself can lead to altered metabolism of medications, such that when rendered euthyroid, patients with hypothyroidism may need alterations in the dose of their medications. For example, initiation of levothyroxine in a hypothyroid patient may enhance the effect of warfarin, which may need dose adjustment.

\section{Triiodothyronine-levothyroxine combination therapy}

A significant minority of hypothyroid patients treated with levothyroxine do not feel completely well and have a poorer quality of life. ${ }^{11}$ There are several possible causes for impaired wellbeing in these patients. Firstly, a number of them have a
TSH outside the normal range, suggesting a suboptimal dosage of levothyroxine. Secondly, given that both hypothyroidism and dysphoria are common diagnoses, there will be a clinical overlap and thus symptoms attributed to hypothyroidism may not improve with treatment. Moreover, patients feeling unwell are more likely to seek medical advice and thus get their thyroid function tested. Thirdly, decreased wellbeing could be due to intrinsic autoimmunity irrespective of the patient's thyroid status. ${ }^{44}$ Lastly, serum TSH may not accurately reflect thyroid hormone concentrations in all target tissues. ${ }^{45}$ In a community-based survey, patients on levothyroxine, despite having normal TSH, were found to have significantly reduced psychological wellbeing as compared with age-matched and gender-matched controls. ${ }^{11}$ Likewise, a cohort study showed poorer quality of life and decreased neurocognitive functioning in 141 hypothyroid patients on adequate doses of levothyroxine as compared with the general population. ${ }^{46}$ Indeed, many patients on levothyroxine do not achieve a physiological Free T3/Free T4 (FT3/FT4) ratio despite serum TSH being within the reference range, ${ }^{47,48}$ suggesting that hepatic and renal conversion of thyroxine to triiodothyronine may be impaired in these patients and this may account for the persistence of their symptoms. Furthermore, in thyroidectomized rats, tissue euthyroidism could be achieved by infusion of both levothyroxine and triiodothyronine and not by levothyroxine alone. ${ }^{49}$ These observations led to the hypothesis that a triiodothyronine-levothyroxine combination is necessary to restore tissue euthyroidism in patients with hypothyroidism.

Several studies have evaluated triiodothyroninelevothyroxine combination therapy in patients with hypothyroidism. An early study from Lithuania showed significant improvement in wellbeing when $50 \mu \mathrm{g}$ of levothyroxine was replaced with $12.5 \mu \mathrm{g}$ of triiodothyronine; ${ }^{50}$ however, several subsequent randomized controlled trials have failed to confirm this effect. A meta-analysis of eleven randomized controlled trials involving 1216 patients concluded that a triiodothyronine-levothyroxine combination is not more effective than levothyroxine alone. ${ }^{51}$ Interestingly, patients in two trials reported a preference for combination therapy despite no objective improvement in wellbeing..$^{52,53} \mathrm{~A}$ major limitation of these studies is that triiodothyronine in the current formulation does not result in a normal physiological profile and the triiodothyronine-levothyroxine combination has been shown to be associated with wide fluctuations in FT3 levels. ${ }^{54}$ Furthermore, it is possible that combination therapy is effective only in a subgroup of patients. This is supported by a recent study, which showed that a common genetic variation in the deiodinase type 2 (DIO2) gene 
is associated with worse baseline quality of life scores in hypothyroid patients on levothyroxine and greater response to the combination therapy. ${ }^{55}$

\section{Desiccated pig thyroid extract}

Desiccated pig thyroid extract (Armour ${ }^{\circledR}$ thyroid; Forest Pharmaceuticals, New York, NY) contains both thyroxine and triiodothyronine in a ratio of about $4: 1$. This is in contrast with human physiological thyroxine and triiodothyronine ratio of $14: 1,{ }^{56}$ and therefore the thyroid extract contains a supraphysiological amount of triiodothyronine. There is no clinical trial evidence to show that it is more effective than levothyroxine.

\section{Triiodothyronine therapy}

A recent randomized double-blind crossover trial has studied the effects of triiodothyronine versus levothyroxine in a cohort of 14 patients with primary hypothyroidism of various etiologies. ${ }^{57}$ Patients received triiodothyronine or levothyroxine three times a day to achieve a target TSH of 0.5-1.5 mIU/L. After 6 weeks of treatment, triiodothyronine was associated with reduced body weight and an improved lipid profile and had no effect on cardiovascular function, insulin sensitivity, or quality of life scores. Further studies with bigger sample sizes and longer follow-up are necessary before this regime could be adopted to treat a subgroup of patients with hypothyroidism in routine clinical practice.

\section{Levothyroxine replacement in special circumstances Subclinical hypothyroidism}

Although subclinical hypothyroidism is a biochemical diagnosis characterized by raised TSH with normal serum thyroid hormone levels, many patients have nonspecific symptoms. Subclinical hypothyroidism is common in the general population (with a prevalence of $4 \%-8 \%$ ) and the prevalence increases with advancing age. ${ }^{1,7}$ It can progress to overt hypothyroidism; the 20-year follow-up study of the Whickham survey has shown that $4.3 \%$ people with raised TSH and positive thyroid antibodies and 3\% with raised TSH without antibodies develop overt hypothyroidism annually. ${ }^{2}$ However, a prospective study has shown that, in about $5 \%$ of patients with subclinical hypothyroidism, TSH returns to normal after 1 year without any treatment. ${ }^{58}$ Likewise, in another large study, $51 \%$ of 3775 patients with TSH $5.5-10 \mathrm{mIU} / \mathrm{L}$ were found to have TSH levels within the reference range when tested 5 years later. ${ }^{59}$ Observational studies have shown inconsistent associations between subclinical hypothyroidism and hyperlipidemia, endothelial dysfunction, cardiovascular disease, and cognitive impairment. ${ }^{7,60-62} \mathrm{~A}$ recent meta-analysis of individual data for over 55,000 subjects from eleven studies showed that subclinical hypothyroidism is associated with an increased risk of cardiovascular events and mortality, particularly if TSH is $10 \mathrm{mIU} / \mathrm{L}$ or higher. ${ }^{61}$ Although randomized controlled trials have shown a trend towards improved lipid profile, endothelial function, and echocardiographic features with levothyroxine treatment in patients with subclinical hypothyroidism, ${ }^{63,64}$ there are no studies to show that levothyroxine reduces cardiovascular events or mortality. Furthermore, a recent randomized controlled trial showed no evidence of improvement of cognitive function with levothyroxine treatment in elderly patients with subclinical hypothyroidism. ${ }^{65}$

Routine use of levothyroxine in subclinical hypothyroidism is controversial. An expert panel has supported the use of levothyroxine in patients with subclinical hypothyroidism if TSH is higher than $10 \mathrm{mIU} / \mathrm{L} .{ }^{66}$ Whilst subclinical hypothyroidism in pregnant women and women planning to conceive should also be treated with levothyroxine, great caution should be exercised when treating elderly patients with this condition (see below). In symptomatic patients with subclinical hypothyroidism and TSH below $10 \mathrm{mIU} / \mathrm{L}$, a 3-6-month trial of levothyroxine is reasonable. ${ }^{39}$ In asymptomatic patients with TSH less than $10 \mathrm{mIU} / \mathrm{L}$, TSH should be monitored annually in the presence of thyroid antibodies and every 3 years if thyroid antibodies are absent. ${ }^{67} \mathrm{~A}$ pragmatic algorithm for the management of subclinical hypothyroidism is shown in Figure 1.

\section{Pregnancy}

Thyroid hormones are essential for the neurological development of the fetus. ${ }^{68}$ Because the fetal thyroid gland starts functioning only after 12-14 weeks of gestation, the fetus relies on maternal thyroid hormones for its early neurological development. Both overt and mild thyroid hormone insufficiency in pregnancy has been shown to be associated with impaired neuropsychological development of the offspring. ${ }^{68-71}$ Furthermore, maternal hypothyroidism is also associated with several other adverse obstetric outcomes, including miscarriage, premature birth, gestational hypertension, and low birth weight ${ }^{72-75}$ and these adverse events may be prevented by optimum thyroid hormone replacement. ${ }^{76}$

Maternal hypothyroidism diagnosed in pregnancy should be corrected as soon as possible by initiating a full 


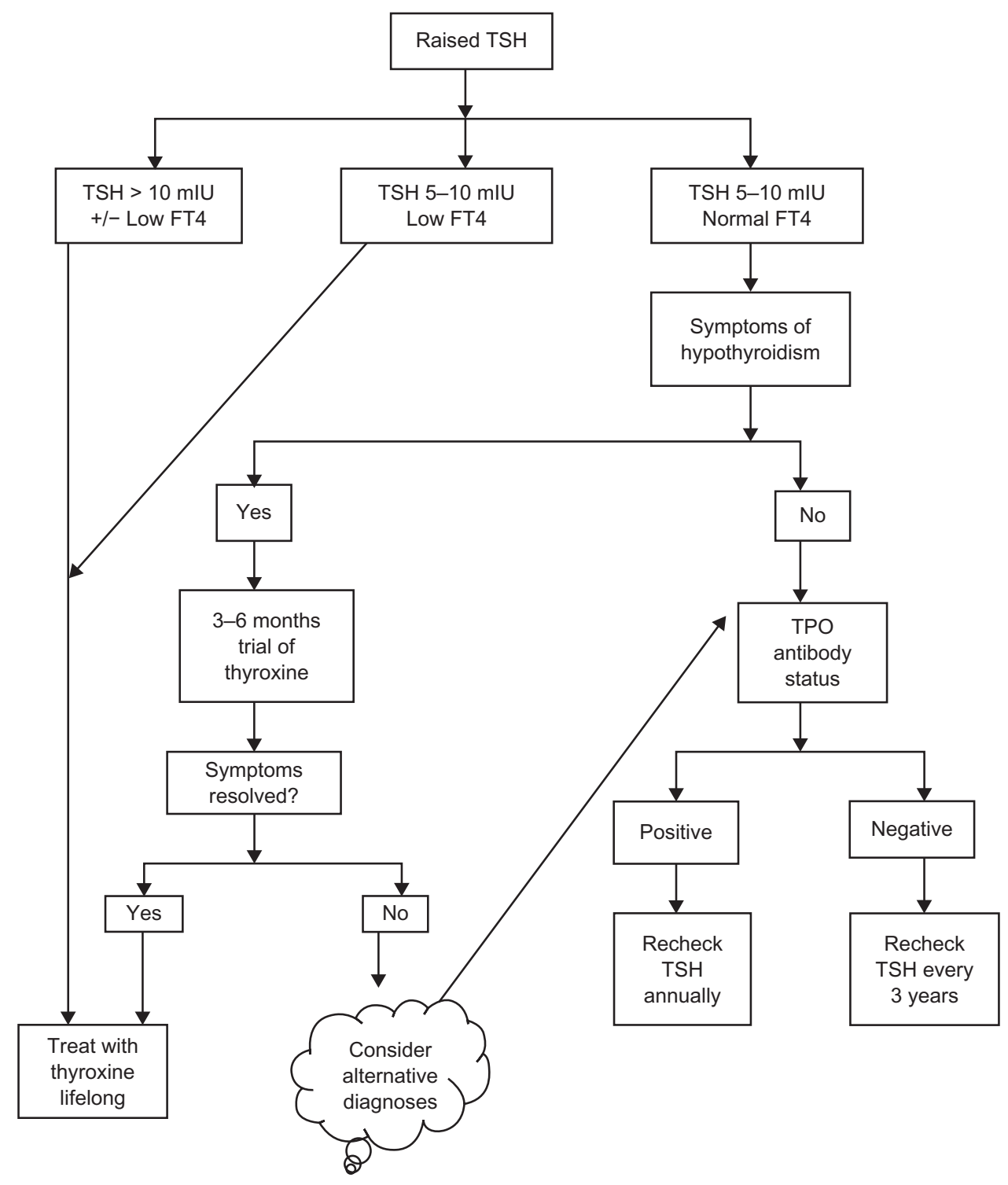

Figure I Algorithm for the pragmatic management of primary hypothyroidism.

Note: Reproduced from British Medical Journal, Vaidya B, Pearce SH, 337, 284-289, 2008 with permission from BMJ Publishing Group Ltd.

Abbreviations: TSH, thyroid stimulating hormone; FT4, free thyroxine; TPO, thyroid peroxidase; mIU, milli-international unit.

replacement dose of levothyroxine (100-150 $\mu \mathrm{g} /$ day or $2.0-2.4 \mu \mathrm{g} / \mathrm{kg}$ body weight/day). ${ }^{19}$ Most women with known hypothyroidism need a $30 \%-50 \%$ increase in the dose of levothyroxine during pregnancy ${ }^{77,78}$ and this increased dose requirement occurs as early as the first 4-6 weeks of gestation. ${ }^{78}$ About a quarter of pregnant hypothyroid women on levothyroxine have high TSH, suggesting underreplacement at their first antenatal visit. ${ }^{79}$ This could, to some extent, be prevented by preconception optimization of levothyroxine dose ${ }^{80}$ and, for hypothyroid women planning pregnancy, levothyroxine dose ideally should be adjusted to keep TSH less than $2.5 \mathrm{mIU} / \mathrm{L}$ before conception. ${ }^{19}$ Thyroid function should be checked as soon as the pregnancy is confirmed to adjust the dose of levothyroxine further.
An alternative approach is to advise the woman to increase the dose of levothyroxine by $30 \%-50 \%{ }^{77}$ or by two tablets per week ${ }^{81}$ as soon as pregnancy is confirmed to avoid any delay in dose increment. Thyroid function should be monitored at regular intervals (every 4-6 weeks) to adjust the dose of levothyroxine to keep TSH under $2.5 \mathrm{mIU} / \mathrm{L}$ in the first trimester and under $3.0 \mathrm{mIU} / \mathrm{L}$ in the second and third trimesters. ${ }^{19}$ Patients will need a reduction of their levothyroxine dose after pregnancy.

There is general consensus that subclinical hypothyroidism in pregnant women should also be treated with levothyroxine. ${ }^{19}$ However, whether all pregnant women should be screened for subclinical hypothyroidism remains controversial. ${ }^{19,79}$ 


\section{Elderly}

The levothyroxine dose requirement gradually decreases with age ${ }^{82,83}$ thought to be due to age-related decreases in thyroxine degradation ${ }^{84}$ and in lean body mass.$^{85}$ Furthermore, levothyroxine replacement may precipitate severe angina or myocardial infarction in an elderly person with asymptomatic ischemic heart disease. Therefore, in people over the age of 65 years, levothyroxine should be started at a small dose ( $25-50$ $\mu \mathrm{g}$ /daily) and dose titration should be carried out slowly.

There is a high prevalence of suboptimal thyroid hormone replacement in the elderly. In a cross-sectional study involving elderly people aged 65 years or over on levothyroxine, $41 \%$ and $16 \%$ had suppressed and raised TSH suggestive of over-replacement and under-replacement, respectively. ${ }^{8}$ The risk of under-replacement of levothyroxine is less certain in this population, with studies showing an association between raised TSH and a lower mortality rate in the very elderly population. ${ }^{26,86,87}$ In contrast, the potential hazards of over-replacement of levothyroxine in the elderly population have been highlighted by the associations between suppressed TSH with reduced bone mineral density ${ }^{88,89}$ as well as increased risk of fractures. ${ }^{90}$ In a recent large cohort study of elderly people above the age of 70 years, levothyroxine treatment has been found to be associated with an increased risk of fractures. ${ }^{91}$ Although thyroid function tests were not analyzed in this study, there was a correlation between the risk of fractures and the dose of levothyroxine, suggesting that the increased fracture risk may be related to over-replacement of levothyroxine. Several epidemiological studies have also shown an association between low or suppressed TSH and atrial fibrillation. ${ }^{92-95}$ However, all of these studies, except the Framingham study, ${ }^{92}$ have excluded patients on levothyroxine and, therefore, it remains unclear whether suppressed TSH due to exogenous levothyroxine is as deleterious to the heart as endogenous subclinical hyperthyroidism. Nevertheless, taken together, these observations underline the importance of careful monitoring and optimizing thyroid hormone replacement in the elderly with hypothyroidism.

\section{Ischemic heart disease}

Prolonged untreated hypothyroidism can lead to persistent bradycardia, an adverse atherogenic lipid profile, and deterioration in myocardial function. However, due to the positive inotropic and chronotropic effects of thyroid hormone on the heart, starting a full dose of levothyroxine could precipitate acute coronary syndrome in hypothyroid patients with previously silent coronary artery stenosis. ${ }^{96}$
Therefore, newly diagnosed hypothyroid patients with ischemic heart disease should be started on a small dose of levothyroxine (12.5-25 $\mu \mathrm{g} /$ day) which is slowly up titrated every $4-6$ weeks in increments of $12.5-25 \mu \mathrm{g}$ /day until euthyroidism is achieved. Some patients may need to increase their antianginal medications to ensure full betablockade, or undergo a coronary revascularization procedure to be able to tolerate an adequate dose of levothyroxine to achieve euthyroidism. ${ }^{97}$ The suggested starting dose regimes of levothyroxine for primary hypothyroidism in different situations are shown in Table 3.

\section{Poor compliance}

In a subset of hypothyroid patients in whom poor compliance with daily dosing of levothyroxine is suspected, a onceweekly dosage of levothyroxine may be used as an alternative. In a randomized crossover trial involving 12 hypothyroid patients, once-weekly administration of seven times the normal daily dose of levothyroxine was shown to be effective and well tolerated..$^{98}$ The study found a higher mean TSH level when patients were on a weekly regime compared with daily dosing, suggesting that a dose slightly higher than the calculated 7 day total may be needed to achieve optimum biochemical control on weekly regime. Because a high dose of levothyroxine may exacerbate angina or precipitate myocardial infarction, the weekly regime of levothyroxine is not appropriate for patients with ischemic heart disease. Furthermore, because the long-term adverse effects of a weekly levothyroxine regime are not known, it should be used only in exceptional cases of noncompliance after other approaches have failed.

\section{Biochemically euthyroid patients with symptoms of hypothyroidism}

Because symptoms of hypothyroidism are nonspecific, many patients have such symptoms without biochemical evidence of hypothyroidism. A randomized, double-blind, placebo-controlled, crossover trial involving 25 patients with symptoms of hypothyroidism but normal biochemistry showed no benefit from levothyroxine in improving wellbeing

Table 3 Suggested starting dose of levothyroxine for primary hypothyroidism in different clinical situations

\begin{tabular}{ll}
\hline Normal otherwise well patients & $\mathrm{I} .6 \mu \mathrm{g} / \mathrm{kg}$ body weight/day \\
Pregnant patients & $2.0-2.4 \mu \mathrm{g} / \mathrm{kg}$ body weight/day \\
Elderly patients & $25-50 \mu \mathrm{g} / \mathrm{day}$ \\
Patients with ischemic heart disease & $12.5-25 \mu \mathrm{g} /$ day \\
Patients on enzyme-inducing drugs & $2.0 \mu \mathrm{g} / \mathrm{kg}$ body weight/day \\
\hline Abbreviations: $\mu \mathrm{g}$, microgram; $\mathrm{kg}$, kilogram.
\end{tabular}


and cognitive function. ${ }^{99}$ Given that levothyroxine is an ineffective treatment and is associated with some adverse outcomes, it should not be used in these patients.

\section{Future possibilities}

After more than 120 years since Murray first successfully treated hypothyroidism with sheep thyroid extract ${ }^{29}$ and numerous subsequent advances in the field, there remain many uncertainties surrounding the management of this common disease. What is the target thyroid function for hypothyroid patients on levothyroxine replacement? What are the long-term outcomes of different target TSH levels on levothyroxine replacement? Should different age groups have different target TSH levels? Should individuals be assessed to determine their personal TSH reference range for future diagnosis and treatment of thyroid dysfunction? Does FT3/FT4 ratio provide additional information about tissue euthyroidism in patients on levothyroxine replacement? Furthermore, although there is increasing evidence from observational studies for an association between subclinical hypothyroidism and the risk of cardiovascular disease-related morbidity and mortality, randomized controlled trial evidence showing that levothyroxine treatment reduces the risk is still lacking. Interestingly, subclinical hypothyroidism can be viewed as an incipient autoimmune disease that develops into overt hypothyroidism over many years. Identification of biomarkers that are better than current thyroid antibody assays at predicting eventual hypothyroidism could lead to targeted intervention to prevent hypothyroidism. Oral selenium supplementation appears to have efficacy in modifying the natural history of Graves' orbitopathy, ${ }^{100}$ and may prove to have immunomodulatory actions in other forms of autoimmune thyroid disease. In pregnancy, results of ongoing and future clinical trials are awaited to inform whether all pregnant women should be screened and treated for subclinical hypothyroidism.

It remains uncertain as to why a minority of hypothyroid patients on levothyroxine continue to have residual symptoms despite apparently adequate replacement, and it is hoped that future studies will clarify this enigma. Moreover, despite several randomized controlled trials showing a lack of benefit of combining triiodothyronine with levothyroxine in such patients, ${ }^{51}$ it is possible that triiodothyronine formulated to mimic the normal physiological profile may have a better outcome. Indeed, a proof of concept study has demonstrated the biochemical efficacy of a combination of long-acting triiodothyronine and levothyroxine on the T4/T3 ratio and TSH over levothyroxine monotherapy. ${ }^{101}$ Further studies are required to see whether this biochemical advantage translates into clinical benefit. Finally, recent genetic studies have shown associations between common genetic variations and thyroid hormone levels, ${ }^{23-26,55,102}$ wellbeing in levothyroxine-treated patients, ${ }^{55}$ and response to triiodothyronine-levothyroxine combination treatment, ${ }^{55}$ opening the door to the possibility of pharmacogenomics. Future genetic studies may help in identifying the subgroup of patients who would benefit from combination therapy.

\section{Acknowledgments}

BV was partly supported in this work by the National Institute for Health Research Collaborations for Leadership in Applied Health Research and Care.

\section{Disclosure}

The authors report no conflicts of interest in this work.

\section{References}

1. Hollowell JG, Staehling NW, Flanders WD, et al. Serum TSH, T(4), and thyroid antibodies in the United States population (1988 to 1994): National Health and Nutrition Examination Survey (NHANES III). J Clin Endocrinol Metab. 2002;87(2):489-499.

2. Vanderpump MP, Tunbridge WM, French JM, et al. The incidence of thyroid disorders in the community: a twenty-year follow-up of the Whickham Survey. Clin Endocrinol (Oxf). 1995;43(1):55-68.

3. Leese GP, Flynn RV, Jung RT, Macdonald TM, Murphy MJ, Morris AD. Increasing prevalence and incidence of thyroid disease in Tayside, Scotland: the Thyroid Epidemiology Audit and Research Study (TEARS). Clin Endocrinol. 2008;68(2):311-316.

4. Tunbridge WM, Evered DC, Hall R, et al. The spectrum of thyroid disease in a community: the Whickham survey. Clin Endocrinol. 1977; 7(6):481-493.

5. Laurberg P. Global or Gaelic epidemic of hypothyroidism? Lancet. 2005;365(9461):738-740

6. Information Centre for Health and Social Care. Prescription Cost Analysis 2010. 2010; Available from: http://www.ic.nhs.uk/pubs/ prescostanalysis2010. Accessed September 1, 2011.

7. Canaris GJ, Manowitz NR, Mayor G, Ridgway EC. The Colorado thyroid disease prevalence study. Arch Intern Med. 2000;160(4):526-534.

8. Somwaru LL, Arnold AM, Joshi N, Fried LP, Cappola AR. High frequency of and factors associated with thyroid hormone overreplacement and under-replacement in men and women aged 65 and over. J Clin Endocrinol Metab. 2009;94(4):1342-1345.

9. Okosieme OE, Belludi G, Spittle K, Kadiyala R, Richards J. Adequacy of thyroid hormone replacement in a general population. QJM. 2011; 104(5):395-401.

10. Parle JV, Franklyn JA, Cross KW, Jones SR, Sheppard MC. Thyroxine prescription in the community: serum thyroid stimulating hormone level assays as an indicator of undertreatment or overtreatment. Br J Gen Pract. 1993;43(368):107-109.

11. Saravanan P, Chau WF, Roberts N, Vedhara K, Greenwood R, Dayan CM. Psychological well-being in patients on 'adequate' doses of 1-thyroxine: results of a large, controlled community-based questionnaire study. Clin Endocrinol (Oxf). 2002;57(5):577-585.

12. Roberts CG, Ladenson PW. Hypothyroidism. Lancet. 2004;363(9411): 793-803.

13. Harris KB, Pass KA. Increase in congenital hypothyroidism in New York State and in the United States. Mol Genet Metab. 2007;91(3): 268-277. 
14. Canaris GJ, Steiner JF, Ridgway EC. Do traditional symptoms of hypothyroidism correlate with biochemical disease? J Gen Intern Med. 1997;12(9):544-550.

15. Spencer CA, Hollowell JG, Kazarosyan M, Braverman LE. National Health and Nutrition Examination Survey III thyroid-stimulating hormone (TSH)-thyroperoxidase antibody relationships demonstrate that TSH upper reference limits may be skewed by occult thyroid dysfunction. J Clin Endocrinol Metab. 2007;92(11): 4236-4240.

16. Wartofsky L, Dickey RA. The evidence for a narrower thyrotropin reference range is compelling. J Clin Endocrinol Metab. 2005;90(9): 5483-5488.

17. Surks MI, Goswami G, Daniels GH. The thyrotropin reference range should remain unchanged. J Clin Endocrinol Metab. 2005;90(9): 5489-5496.

18. Brabant G, Beck-Peccoz P, Jarzab B, et al. Is there a need to redefine the upper normal limit of TSH? Eur J Endocrinol. 2006;154(5): 633-637.

19. Abalovich M, Amino N, Barbour LA, et al. Management of thyroid dysfunction during pregnancy and postpartum: an Endocrine Society Clinical Practice Guideline. J Clin Endocrinol Metab. 2007; 92(8 Suppl):S1-S47.

20. Stagnaro-Green A, Abalovich M, Alexander E, et al. Guidelines of the American thyroid association for the diagnosis and management of thyroid disease during pregnancy and postpartum. Thyroid. 2011;21(10):1081-1125.

21. Surks MI, Boucai L. Age- and race-based serum thyrotropin reference limits. J Clin Endocrinol Metab. 2010;95(2):496-502.

22. Andersen S, Pedersen KM, Bruun NH, Laurberg P. Narrow individual variations in serum $\mathrm{T}(4)$ and $\mathrm{T}(3)$ in normal subjects: a clue to the understanding of subclinical thyroid disease. J Clin Endocrinol Metab. 2002;87(3):1068-1072.

23. Arnaud-Lopez L, Usala G, Ceresini G, et al. Phosphodiesterase 8B gene variants are associated with serum TSH levels and thyroid function. Am J Hum Genet. 2008;82(6):1270-1280.

24. Medici M, van der Deure WM, Verbiest M, et al. A large-scale association analysis of 68 thyroid hormone pathway genes with serum TSH and FT4 levels. Eur J Endocrinol. 2011;164(5):781-788.

25. Taylor PN, Panicker V, Sayers A, et al. A meta-analysis of the associations between common variation in the PDE8B gene and thyroid hormone parameters, including assessment of longitudinal stability of associations over time and effect of thyroid hormone replacement. Eur J Endocrinol. 2011;164(5):773-780.

26. Atzmon G, Barzilai N, Surks MI, Gabriely I. Genetic predisposition to elevated serum thyrotropin is associated with exceptional longevity. J Clin Endocrinol Metab. 2009;94(12):4768-4775.

27. Shields BM, Freathy RM, Knight BA, et al. Phosphodiesterase 8B gene polymorphism is associated with subclinical hypothyroidism in pregnancy. $J$ Clin Endocrinol Metab. 2009;94(11): 4608-4612.

28. Lindholm J, Laurberg P. Hypothyroidism and thyroid substitution: historical aspects. J Thyroid Res. 2011;2011:809341.

29. Murray GR. Note on the treatment of myxoedema by hypodermic injections of an extract of the thyroid gland of a sheep. $\mathrm{Br}$ Med $\mathrm{J}$ 1891;2(1606):796-797.

30. Fox EL. A case of myxoedema treated by taking extract of thyroid by the mouth. Br Med J. 1892;2(1661):941.

31. Gross J, Pitt-Rivers R. 3:5:3' -triiodothyronine. 1. Isolation from thyroid gland and synthesis. Biochem J. 1953;53(4):645-650.

32. Roos A, Linn-Rasker SP, van Domburg RT, Tijssen JP, Berghout A. The starting dose of levothyroxine in primary hypothyroidism treatment: a prospective, randomized, double-blind trial. Arch Intern Med. 2005;165(15):1714-1720.

33. Bolk N, Visser TJ, Kalsbeek A, van Domburg RT, Berghout A. Effects of evening vs morning thyroxine ingestion on serum thyroid hormone profiles in hypothyroid patients. Clin Endocrinol. 2007;66(1): 43-48.
34. Bolk N, Visser TJ, Nijman J, Jongste IJ, Tijssen JG, Berghout A. Effects of evening vs morning levothyroxine intake: a randomized double-blind crossover trial. Arch Intern Med. 2010;170(22):1996-2003.

35. Elliott DP. Effect of levothyroxine administration time on serum TSH in elderly patients. Ann Pharmacother. 2001;35(5):529-532.

36. Bach-Huynh TG, Nayak B, Loh J, Soldin S, Jonklaas J. Timing of levothyroxine administration affects serum thyrotropin concentration. J Clin Endocrinol Metab. 2009;94(10):3905-3912.

37. Rajput R, Chatterjee S, Rajput M. Can levothyroxine be taken as evening dose? Comparative evaluation of morning versus evening dose of levothyroxine in treatment of hypothyroidism. J Thyroid Res. 2011;2011:505239.

38. Viswanath AK, Avenell A, Philip S, et al. Is annual surveillance of all treated hypothyroid patients necessary? BMC Endocr Disord. 2007; 7:4.

39. Vaidya B, Pearce SH. Management of hypothyroidism in adults. BMJ. 2008;337:a801.

40. Carr D, McLeod DT, Parry G, Thornes HM. Fine adjustment of thyroxine replacement dosage: comparison of the thyrotrophin releasing hormone test using a sensitive thyrotrophin assay with measurement of free thyroid hormones and clinical assessment. Clin Endocrinol. 1988;28(3):325-333.

41. Walsh JP, Ward LC, Burke V, et al. Small changes in thyroxine dosage do not produce measurable changes in hypothyroid symptoms, wellbeing, or quality of life: results of a double-blind, randomized clinical trial. J Clin Endocrinol Metab. 2006;91(7):2624-2630.

42. Boeving A, Paz-Filho G, Radominski RB, Graf H, de Carvalho GA. Low-normal or high-normal thyrotropin target levels during treatment of hypothyroidism: a prospective, comparative study. Thyroid. 2011; 21(4):355-360.

43. Arafah BM. Increased need for thyroxine in women with hypothyroidism during estrogen therapy. $N$ Engl J Med. 2001;344(23):1743-1749.

44. Saravanan P, Dayan CM. Understanding thyroid hormone action and the effects of Thyroid hormone replacement - just the beginning not the end. Hot Thyroidology. 2004; 1. Available from: http://www.hotthyroidology. com/editorial_135.html. Accessed October 5, 2011.

45. Meier C, Trittibach P, Guglielmetti M, Staub JJ, Muller B. Serum thyroid stimulating hormone in assessment of severity of tissue hypothyroidism in patients with overt primary thyroid failure: cross sectional survey. BMJ. 2003;326(7384):311-312.

46. Wekking EM, Appelhof BC, Fliers E, et al. Cognitive functioning and well-being in euthyroid patients on thyroxine replacement therapy for primary hypothyroidism. Eur J Endocrinol. 2005;153(6):747-753.

47. Jonklaas J, Davidson B, Bhagat S, Soldin SJ. Triiodothyronine levels in athyreotic individuals during levothyroxine therapy. JAMA. 2008; 299(7):769-777.

48. Gullo D, Latina A, Frasca F, Le Moli R, Pellegriti G, Vigneri R. Levothyroxine monotherapy cannot guarantee euthyroidism in all athyreotic patients. PLoS One. 2011;6(8):e22552.

49. Escobar-Morreale HF, Obregon MJ, Escobar del Rey F, Morreale de Escobar G. Replacement therapy for hypothyroidism with thyroxine alone does not ensure euthyroidism in all tissues, as studied in thyroidectomized rats. J Clin Invest. 1995;96(6):2828-2838.

50. Bunevicius R, Kazanavicius G, Zalinkevicius R, Prange AJ Jr. Effects of thyroxine as compared with thyroxine plus triiodothyronine in patients with hypothyroidism. $N$ Engl J Med. 1999;340(6): 424-429.

51. Grozinsky-Glasberg S, Fraser A, Nahshoni E, Weizman A, Leibovici L. Thyroxine-triiodothyronine combination therapy versus thyroxine monotherapy for clinical hypothyroidism: meta-analysis of randomized controlled trials. J Clin Endocrinol Metab. 2006;91(7): 2592-2599.

52. Appelhof BC, Peeters RP, Wiersinga WM, et al. Polymorphisms in type 2 deiodinase are not associated with well-being, neurocognitive functioning, and preference for combined thyroxine $/ 3,5,3^{\prime}$ triiodothyronine therapy. J Clin Endocrinol Metab. 2005;90(11): 6296-6299. 
53. Escobar-Morreale HF, Botella-Carretero JI, Gomez-Bueno M, Galan JM, Barrios V, Sancho J. Thyroid hormone replacement therapy in primary hypothyroidism: a randomized trial comparing L-thyroxine plus liothyronine with L-thyroxine alone. Ann Intern Med. 2005; 142(6):412-424.

54. Saravanan P, Siddique H, Simmons DJ, Greenwood R, Dayan CM. Twenty-four hour hormone profiles of TSH, Free T3 and free T4 in hypothyroid patients on combined T3/T4 therapy. Exp Clin Endocrinol Diabetes. 2007;115(4):261-267.

55. Panicker V, Saravanan P, Vaidya B, et al. Common variation in the DIO2 gene predicts baseline psychological well-being and response to combination thyroxine plus triiodothyronine therapy in hypothyroid patients. J Clin Endocrinol Metab. 2009;94(5):1623-1629.

56. Escobar-Morreale HF, Botella-Carretero JI, Escobar del Rey F, Morreale de Escobar G. REVIEW: Treatment of hypothyroidism with combinations of levothyroxine plus liothyronine. J Clin Endocrinol Metab. 2005;90(8):4946-4954.

57. Celi FS, Zemskova M, Linderman JD, et al. Metabolic effects of liothyronine therapy in hypothyroidism: a randomized, double-blind, crossover trial of liothyronine versus levothyroxine. J Clin Endocrinol Metab. 2011;96:3466-3474.

58. Parle JV, Franklyn JA, Cross KW, Jones SC, Sheppard MC. Prevalence and follow-up of abnormal thyrotrophin (TSH) concentrations in the elderly in the United Kingdom. Clin Endocrinol. 1991;34(1):77-83.

59. Meyerovitch J, Rotman-Pikielny P, Sherf M, Battat E, Levy Y, Surks MI. Serum thyrotropin measurements in the community: fiveyear follow-up in a large network of primary care physicians. Arch Intern Med. 2007;167(14):1533-1538.

60. Lekakis J, Papamichael C, Alevizaki M, et al. Flow-mediated, endothelium-dependent vasodilation is impaired in subjects with hypothyroidism, borderline hypothyroidism, and high-normal serum thyrotropin (TSH) values. Thyroid. 1997;7(3):411-414.

61. Rodondi N, den Elzen WP, Bauer DC, et al. Subclinical hypothyroidism and the risk of coronary heart disease and mortality. JAMA. 2010; 304(12):1365-1374.

62. Ceresini G, Lauretani F, Maggio M, et al. Thyroid function abnormalities and cognitive impairment in elderly people: results of the Invecchiare in Chianti study. J Am Geriatr Soc. 2009;57(1):89-93.

63. Villar HC, Saconato H, Valente O, Atallah AN. Thyroid hormone replacement for subclinical hypothyroidism. Cochrane Database Syst Rev. 2007(3):CD003419.

64. Razvi S, Ingoe L, Keeka G, Oates C, McMillan C, Weaver JU. The beneficial effect of L-thyroxine on cardiovascular risk factors, endothelial function, and quality of life in subclinical hypothyroidism: randomized, crossover trial. J Clin Endocrinol Metab. 2007;92(5):1715-1723.

65. Parle J, Roberts L, Wilson S, et al. A randomized controlled trial of the effect of thyroxine replacement on cognitive function in community-living elderly subjects with subclinical hypothyroidism: the Birmingham Elderly Thyroid study. J Clin Endocrinol Metab. 2010;95(8):3623-3632.

66. Surks MI, Ortiz E, Daniels GH, et al. Subclinical thyroid disease: scientific review and guidelines for diagnosis and management. JAMA. 2004;291(2):228-238.

67. Association for Clinical Biochemistry, British Thyroid Association, British Thyroid Foundation. UK guidelines for the use of thyroid function tests. 2006. Available from: http://www.british-thyroid-association. org/info-for-patients/Docs/TFT_guideline_final_version_July_2006. pdf. Accessed September 1, 2011.

68. de Escobar GM, Obregon MJ, del Rey FE. Maternal thyroid hormones early in pregnancy and fetal brain development. Best Pract Res Clin Endocrinol Metab. 2004;18(2):225-248.

69. Haddow JE, Palomaki GE, Allan WC, et al. Maternal thyroid deficiency during pregnancy and subsequent neuropsychological development of the child. N Engl J Med. 1999;341(8):549-555.

70. Pop VJ, Kuijpens JL, van Baar AL, et al. Low maternal free thyroxine concentrations during early pregnancy are associated with impaired psychomotor development in infancy. Clin Endocrinol. 1999;50(2):149-155.
71. Henrichs J, Bongers-Schokking JJ, Schenk JJ, et al. Maternal thyroid function during early pregnancy and cognitive functioning in early childhood: the generation R study. J Clin Endocrinol Metab. 2010; 95(9):4227-4234.

72. Allan WC, Haddow JE, Palomaki GE, et al. Maternal thyroid deficiency and pregnancy complications: implications for population screening. J Med Screen. 2000;7(3):127-130.

73. Abalovich M, Gutierrez S, Alcaraz G, Maccallini G, Garcia A, Levalle O. Overt and subclinical hypothyroidism complicating pregnancy. Thyroid. 2002;12(1):63-68.

74. Casey BM, Dashe JS, Wells CE, et al. Subclinical hypothyroidism and pregnancy outcomes. Obstet Gynecol. 2005;105(2):239-245.

75. Krassas GE, Poppe K, Glinoer D. Thyroid function and human reproductive health. Endocrine Reviews. 2010;31(5):702-755.

76. Negro R, Schwartz A, Gismondi R, Tinelli A, Mangieri T, Stagnaro-Green A. Increased pregnancy loss rate in thyroid antibody negative women with TSH levels between 2.5 and 5.0 in the first trimester of pregnancy. J Clin Endocrinol Metab. 2010;95(9):E44-E48.

77. Mandel SJ, Larsen PR, Seely EW, Brent GA. Increased need for thyroxine during pregnancy in women with primary hypothyroidism. $N$ Engl J Med. 1990;323(2):91-96.

78. Alexander EK, Marqusee E, Lawrence J, Jarolim P, Fischer GA, Larsen PR. Timing and magnitude of increases in levothyroxine requirements during pregnancy in women with hypothyroidism. $N$ Engl $J$ Med. 2004; 351(3):241-249.

79. Vaidya B, Anthony S, Bilous M, et al. Detection of thyroid dysfunction in early pregnancy: Universal screening or targeted high-risk case finding? J Clin Endocrinol Metab. 2007;92(1):203-207.

80. Rotondi M, Mazziotti G, Sorvillo F, et al. Effects of increased thyroxine dosage pre-conception on thyroid function during early pregnancy. Eur $J$ Endocrinol. 2004;151(6):695-700.

81. Yassa L, Marqusee E, Fawcett R, Alexander EK. Thyroid hormone early adjustment in pregnancy (the THERAPY) trial. J Clin Endocrinol Metab. 2010;95(7):3234-3241.

82. Rosenbaum RL, Barzel US. Levothyroxine replacement dose for primary hypothyroidism decreases with age. Ann Intern Med. 1982; 96(1):53-55.

83. Sawin CT, Herman T, Molitch ME, London MH, Kramer SM. Aging and the thyroid. Decreased requirement for thyroid hormone in older hypothyroid patients. Am J Med. 1983;75(2):206-209.

84. Gregerman RI, Gaffney GW, Shock NW, Crowder SE. Thyroxine turnover in euthyroid man with special reference to changes with age. J Clin Invest. 1962;41:2065-2074.

85. Cunningham JJ, Barzel US. Lean body mass is a predictor of the daily requirement for thyroid hormone in older men and women. JAm Geriatr Soc. 1984;32(3):204-207.

86. Gussekloo J, van Exel E, de Craen AJ, Meinders AE, Frolich M, Westendorp RG. Thyroid status, disability and cognitive function, and survival in old age. JAMA. 2004;292(21):2591-2599.

87. Atzmon G, Barzilai N, Hollowell JG, Surks MI, Gabriely I. Extreme longevity is associated with increased serum thyrotropin. $J$ Clin Endocrinol Metab. 2009;94(4):1251-1254.

88. Faber J, Galloe AM. Changes in bone mass during prolonged subclinical hyperthyroidism due to L-thyroxine treatment: a meta-analysis. Eur $J$ Endocrinol. 1994;130(4):350-356.

89. Uzzan B, Campos J, Cucherat M, Nony P, Boissel JP, Perret GY. Effects on bone mass of long term treatment with thyroid hormones: a metaanalysis. J Clin Endocrinol Metab. 1996;81(12):4278-4289.

90. Bauer DC, Ettinger B, Nevitt MC, Stone KL. Risk for fracture in women with low serum levels of thyroid-stimulating hormone. Ann Intern Med. 2001;134(7):561-568.

91. Turner MR, Camacho X, Fischer HD, et al. Levothyroxine dose and risk of fractures in older adults: nested case-control study. $B M J$. 2011;342:d2238.

92. Sawin CT, Geller A, Wolf PA, et al. Low serum thyrotropin concentrations as a risk factor for atrial fibrillation in older persons. $N$ Engl J Med. 1994;331(19):1249-1252. 
93. Cappola AR, Fried LP, Arnold AM, et al. Thyroid status, cardiovascular risk, and mortality in older adults. JAMA. 2006;295(9): 1033-1041.

94. Gammage MD, Parle JV, Holder RL, et al. Association between serum free thyroxine concentration and atrial fibrillation. Arch Intern Med. 2007;167(9):928-934.

95. Vadiveloo T, Donnan PT, Cochrane L, Leese GP. The Thyroid Epidemiology, Audit, and Research Study (TEARS): morbidity in patients with endogenous subclinical hyperthyroidism. J Clin Endocrinol Metab. 2011;96(5):1344-1351.

96. Levine HD. Compromise therapy in the patient with angina pectoris and hypothyroidism. A clinical assessment. Am J Med. 1980;69(3): 411-418.

97. Ellyin FM, Kumar Y, Somberg JC. Hypothyroidism complicated by angina pectoris: therapeutic approaches. J Clin Pharmacol. 1992; 32(9):843-847.
98. Grebe SK, Cooke RR, Ford HC, et al. Treatment of hypothyroidism with once weekly thyroxine. J Clin Endocrinol Metab. 1997;82(3): $870-875$.

99. Pollock MA, Sturrock A, Marshall K, et al. Thyroxine treatment in patients with symptoms of hypothyroidism but thyroid function tests within the reference range: randomised double blind placebo controlled crossover trial. BMJ. 2001;323(7318):891-895.

100. Marcocci C, Kahaly GJ, Krassas GE, et al. Selenium and the course of mild Graves' orbitopathy. N Engl J Med. 2011;364(20):1920-1931.

101. Hennemann G, Docter R, Visser TJ, Postema PT, Krenning EP. Thyroxine plus low-dose, slow-release triiodothyronine replacement in hypothyroidism: proof of principle. Thyroid. 2004;14(4): 271-275.

102. Panicker V, Cluett $C$, Shields B, et al. A common variation in deiodinase 1 gene DIO1 is associated with the relative levels of free thyroxine and triiodothyronine. J Clin Endocrinol Metab. 2008;93(8): 3075-3081.

\section{Publish your work in this journal}

Drug Design, Development and Therapy is an international, peerreviewed open-access journal that spans the spectrum of drug design and development through to clinical applications. Clinical outcomes, patient safety, and programs for the development and effective, safe, and sustained use of medicines are a feature of the journal, which has also been accepted for indexing on PubMed Central. The manuscript management system is completely online and includes a very quick and fair peer-review system, which is all easy to use. Visit http://www.dovepress.com/testimonials.php to read real quotes from published authors.

Submit your manuscript here: http://www.dovepress.com/drug-design-development-and-therapy-journal 